\title{
Academic integrity of university students during emergency remote online assessment: An exploration of student voices
}

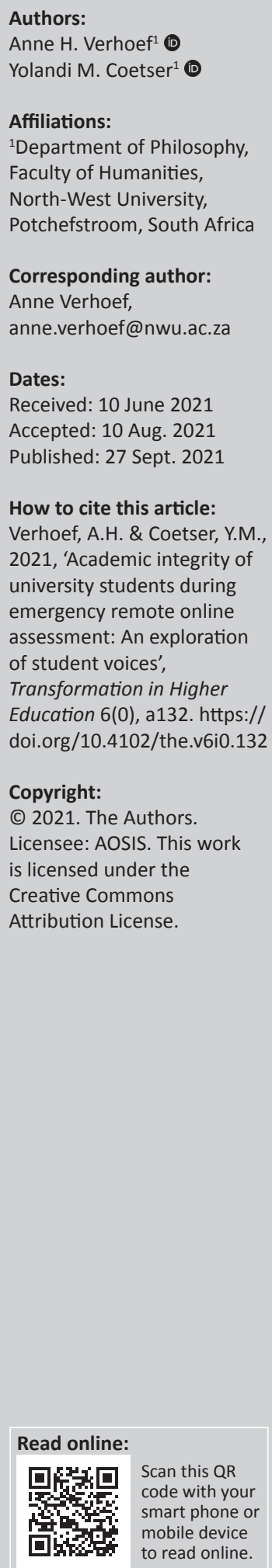

Background: This article examines the phenomenon of academic integrity during the coronavirus disease 2019 (COVID-19) pandemic, with particular reference to emergency online assessments in 2020 .

Aim: It explores academic dishonesty, cheating and plagiarism of university students during emergency remote online assessment, from the perspective of South African students.

Setting and Methodology: The authors explore the approaches of different universities worldwide, as well as the extant literature on the topic. An examination of the current literature related explicitly to the COVID-19 online assessments reveals a dearth of engagement by researchers in the South African context. In order to address this lacuna, the authors rely on data generated from an institutional forum on academic dishonesty at a University in South Africa. It focuses specifically on the voices of students presented during the forum, which explained both why students are dishonest and ways to curb dishonesty.

Results and Conclusion: The data generated show whilst some students were dishonest due to pandemic-related issues (like lack of monitoring), there are also other reasons, such as lack of time management, feeling overwhelmed and stressed and struggling with technology that contributes to student dishonesty. Students suggest that assessments be approached differently online to curb academic dishonesty. The paper concludes by providing some fundamental changes needed to address academic dishonesty.

Keywords: academic integrity; academic dishonesty; emergency remote online assessments; South Africa; cheating; online assessments; university students; plagiarism; COVID-19.

\section{Introduction}

The question of academic integrity quickly gained prominence when global coronavirus disease 2019 (COVID-19) restrictions forced higher education institutions to switch to online teaching, learning and assessment in 2020:

[I]n contrast to experiences that are planned from the beginning and designed to be online, emergency remote teaching (ERT) is a temporary shift of instructional delivery to an alternate delivery mode due to crisis circumstances. (Hodges et al. 2020:9)

At the height of lockdown measures in April 2020, almost 1.5 billion learners, or 83.8\%, were affected by the pandemic and subsequent closure of educational institutions (Gamage, De Silva \& Gunawardhana 2020:1; UNESCO 2021). These lockdowns meant face-to-face teaching, sit-down assessments and examinations with invigilators had to be suspended. Lecturers and students were unprepared for the rapid movement that had to be made, especially about online assessment. In most cases, no account had been taken of the requirements of online assessment when the assessments were designed. Without invigilators on hand to detect any dishonesty, online assessments opened the door to new forms of academic cheating. At this point, when the pandemic has already entered is the second year, there is no evidence that online assessment is sufficiently reliable. Despite lecturers being given training in online assessment by their universities and their making every effort to curb cheating, questions remain on the extent of cheating and the degree to which universities have successfully countered this problem.

This article examines the phenomenon of academic integrity during the COVID-19 pandemic. It focuses on online assessment and explores themes of academic dishonesty, cheating and plagiarism as related to online assessments during emergency remote online academic programmes. In order to do so, the approaches of different universities worldwide were surveyed, 
as well as the extant literature on the topic. An examination of the current literature related explicitly to the COVID-19 and online assessments (Bilen \& Matros 2020; Eaton 2020; Elzainy, El Sadik \& Al Abdulmonem 2020; Gamage et al. 2020; Jose 2021; $\mathrm{Ng}$ 2021; Reedy et al. 2021) points to a dearth of engagement in the South African context (Ngqondi, Maoneke \& Mauwa 2021). In order to address this particular deficiency, data were collected from an institutional forum on academic dishonesty at a University in South Africa in 2020. By addressing a global phenomenon - that is academic dishonesty during emergency remote online assessments - from an underexplored geographical milieu - South Africa - this article contributes to the existing body of literature.

This article has four constituent parts. The first examines the phenomenon of academic integrity during a pandemic. The second outlines the research design. The third discusses the data under two headings: 'Why is there dishonesty during (online) assessment?' and 'What will stop students cheating during online assessment?'. Finally, this article offers some concluding insights into the way forward.

\section{Academic integrity amidst a pandemic}

Before we continue, it is helpful to define academic dishonesty. Whilst there are competing definitions, academic dishonesty may be said to be made up of several harmful behaviours in which students intentionally use unethical practices or deception in their academic work. These behaviours breach accepted standards and rules and often provide students with an unfair advantage over other students. Some examples of academic dishonesty are cheating on assignments, plagiarism, providing fraudulent excuses for missed assessments or paying someone to complete an assessment on one's behalf (Marques, Reis \& Gomes 2019:170). Newton and Lang (2016) note that:

[B] espoke 'custom essays' are available from hundreds of companies, and many online contract employment sites have sections for 'academic writing'. 'Essay mills' may contain many thousands of prewritten assignments, available for some form of fee. (p. 249)

Similar points are made by Wallace and Newton (2014) and Owings and Nelson (2014).

It is not only academic dishonesty that warrants definition but also the opposite: academic integrity. Gamage et al. (2020:2) maintain that academic integrity is a commitment to upholding six fundamental values: 'honesty, trust, fairness, respect, responsibility and courage'. This is reiterated by the International Center for Academic Integrity (ICAI), which defines academic integrity as 'a commitment to six fundamental values: honesty, trust, fairness, respect, responsibility, and courage'. The ICAI (2021) argues that ' $[b]$ y embracing these fundamental values, instructors, students, staff, and administrators create effective scholarly communities where integrity is a touchstone' (p. 4). In its policy on academic integrity, the North-West University defines academic integrity as:
[T] he adherence to ethics of honest scholarship and the ability to work independently; also to give credit to the ideas of others and the re-use of one's own previous work, and the submission of original research products for assessment, examination and review. (NWU Policy on Academic Integrity 2018:4)

What becomes apparent from these definitions is that integrity is the cornerstone of the quality of academic activity - in the case of students and lecturers. Whilst lecturers need to complete their duties with responsibility, so too the students need to be honest when submitting assignments. If lecturers cannot trust their students' submissions, their workload is increased. They have to add being a private investigator to their role as an evaluator of the student's work.

Traditionally, often venue-based assessment opportunities hold students to a certain degree of honesty and integrity. Being in a controlled environment, having vigilant invigilators on duty and having no recourse to notes, phones or laptops make it difficult for students to cheat. In an online assessment environment, especially one to which a rapid move was made, the possibility of dishonesty increases. Students can (and probably do) use their books, browse the Internet or consult with friends during tests. Assignments and tests can be outsourced to senior students or other experts. Students are able to send screenshots or images of test questions via text messages, and acquire answers or work with other students to find answers for test or examination questions that were designed to be taken individually. Plagiarism, long a problem with regard to written assignments, has now become a matter of concern during online examinations. These increased opportunities for dishonesty place a heavy burden on lecturers, who might not know how to identify dishonesty in assessments or, more worryingly, how to counter attempts at dishonesty. There is also the matter of design. The early online assessments, which were designed for traditional face-to-face environments, were often quite ineptly adapted for the online environment.

Undoubtedly, the possibility of being dishonest and cheating increased when an online assessment was introduced. The question is, however, whether the level of academic dishonesty has actually increased. It would be extremely difficult to answer this question accurately. Part of the reason is that there are numerous possible ways for students to be dishonest. If we were to ask the students, they are likely to be reluctant to admit their dishonest behaviour for fear of repercussions. Given that there are millions of students worldwide, the scope of such an empirical investigation would be daunting.

Some research points to evidence of the advent of a particular type of academic dishonesty since March 2020, when lockdowns were implemented worldwide. Sarah Eaton of the University of Calgary in Canada found that there was aggressive marketing of 'commercial file-sharing and contract cheating companies during the pandemic', raising significant concerns about academic integrity (Eaton 2020:82). 
This is echoed in the report by the Quality Assurance Agency (QAA) in the United Kingdom that found that ' $[t]$ he COVID-19 pandemic has seen essay mills target students as they seek to take advantage of the uncertainty and anxiety that might arise as a consequence' (QAA 2020:2). However, Eaton (2020) also points to a robust body of literature that indicates that 'contrary to popular myths, there is actually less academic misconduct in online courses compared with face-to-face delivery' and that academic misconduct is higher during face-to-face classes (p. 81). The literature she cites was written well before the COVID-19 pandemic and so does not take account of the emergency remote learning situation of 2020. Eaton (2020:81) notes that in these studies, the 'students enrolled in online courses were typically older than their face-to-face counterparts'. She cites studies that have shown that academic misconduct decreases as students mature. She also refers to the emergency remote online teaching of 2020 when all students were online. Before discussing this, she provides a useful distinction between online learning and emergency remote learning (Eaton 2020):

$[W]$ hen classes rapidly transitioned from face-to-face to alternate delivery during the coronavirus pandemic, the nature of teaching and learning online was unlike what those with experience with e-learning knew it to be. The technological tools used for delivery may have been the same, but suddenly we had thousands of students and educators working in online environments who had little to no training, experience, or in some cases, willingness. Let's be clear: emergency remote learning is not the same thing as online learning. In the former, panic underpins a rapid response to ensure learning continuity in an uncertain environment. (p. 81)

In their article on 'Safeguarding Academic Integrity', specifically focused on online delivery and assessment during COVID-19, Gamage et al. (2020), interestingly enough, do not cite any research data on dishonesty, perhaps again because it is so difficult to measure dishonesty and cheating. They do, however, point out that 'assessment restrictions are harder to enforce remotely' (Gamage et al. 2020:10). They also refer to a study by the Irish Universities Association (IUA) (2020) on whether online students cheat, which states:

$[R]$ esearch indicates that online students are no more likely to cheat on assessments than campus-based students. This is because the same opportunities exist for cheating on homework, take-home assignments, essays, group work, etc. ... However, the exception to this might be in exams, where students are used to being monitored under exam conditions. Students are more likely to cheat when they are under pressure, when they have opportunity and when it is unlikely that there will be consequences, if caught. (p. 1)

A cross-sectional study in medical science faculties at the Jordan University of Science and Technology indicated that students do not prefer E-exams because examination 'dishonesty/misconduct appears as one of the major challenges with remote E-exams' (Elsalem et al. 2021:326) during the COVID-19 pandemic. Although it is challenging (and perhaps even impossible) to provide convincing empirical evidence that dishonesty and cheating have increased because of online teaching and assessment (especially with COVID-19), it is clear that the 'potential for a higher incidence of academic dishonesty' (Harmon \& Lambrinos 2008:123) in online courses exists. A question that arises from this conclusion concerns the motivation behind instances of academic dishonesty.

As already indicated, academic dishonesty is not a new phenomenon. In 2010, for example, findings 'revealed most students cheat occasionally, but only a small minority are flagrant cheaters; and these flagrant cheaters are five times more likely to be cheating via contemporary methods' (Witherspoon, Maldonado \& Lacey 2010:2). Online assessment may have increased the level of dishonesty and cheating. Perhaps we need to ask a different question. A study by Donald McCabe and the ICAI in 2012 showed that $68 \%$ of undergraduate students and $43 \%$ of graduate students admitted to cheating during written tests (ICAI 2012; Rodchua 2017:168). The statistics might be higher now with the advent of the widespread use of online assessment, but the real question is why do these students cheat, and how can it be fundamentally changed? Before attempts are made to curb the dishonest behaviour of students, the reasons for cheating need to be better understood.

Three things seem clear. The first is that much of the literature surrounding the COVID-19 pandemic and online assessments emanates from the Global North. There is a dearth of literature from the Global South in general; South Africa, more specifically, does not seem to be part of this critical debate. Although academic dishonesty might not be a new phenomenon, there seems to have been a heightened reason for concern during the emergency remote online teaching and assessment during the 2020 academic year in one site. This unique iteration necessitates a fresh look at this phenomenon, considering the distinctive considerations of this particular academic year. The following section outlines the particular research design we employed to examine the phenomenon of academic integrity during online assessments. Finally, the jury is still out on whether academic dishonesty has, in fact, increased during the emergency remote online learning period of 2020. Whilst some of the above texts suggest that there might have been an increase, others indicate that there has not. This lack of clarity suggests that the topic of academic integrity warrants further investigation.

In what follows, we unpack the methodology used in this article.

\section{Research design and methodology}

At the beginning of this article, we stated that this article examines the phenomenon of academic integrity during the COVID-19 pandemic, focusing specifically on online assessments. Put differently, this paper explores themes of academic dishonesty, cheating and plagiarism as related to online assessments during emergency remote online teaching. 
As dishonesty is challenging to quantify and measure, this research question lent itself to qualitative research design.

As the research focuses on a specific phenomenon, an interpretivist paradigm was chosen. An interpretivist paradigm is post-positivist, in that it rejects 'the belief that human behaviour is governed by general, universal laws and characterised by underlying regularities' (Cohen et al. 2018:17). Interpretivism places an emphasis on subjective meaning-making, holding the view that 'the social world can only be understood from the standpoint of the individuals who are part of the ongoing action being investigated' (Cohen et al. 2018:17).

The methodology that we used is phenomenology. As Cohen et al. (2018:20-21) say, phenomenology holds that subjective consciousness has primary importance, that immediate experiences ought to be documented and described, that actions and interactions have social and cultural situatedness and that one can gain direct knowledge through a type of reflection. The phenomenological approach is appropriate, as the students' immediate experience and subjective awareness about academic dishonesty during the emergency online assessment are of crucial importance. Direct knowledge of academic dishonesty is gained through the engagement with the students' reflection on their experience during this time.

\section{Sampling and data generation}

Data for this paper were generated from a forum held at a South African University on 27 May 2021 on academic dishonesty and cheating. The forum was recorded, an existing video was used (available at https://www. youtube.com/watch? $\mathrm{v}=\mathrm{SjNtOXqpJAo)}$ to generate data. This particular video was used because to our' knowledge, this forum is the only one in South Africa that specifically addresses the issue of academic dishonesty during the rapid transition to online learning. This means that this forum represents a valuable source of information to address the dearth of South African perspectives. Within this forum, a variety of perspectives were presented - from students to lecturers to management. We used purposive sampling for the research reported in this article. Purposive sampling does not purport to offer a representative sample, 'but rather to hone in on particular phenomena and/or processes' (Robinson 2014). Of particular interest for this article was students' perspectives. During this event, the voices of 10 anonymised students were heard. These were undergraduate students from all campuses and all faculties within the university, but because of their anonymity, specific demographic information is not available. The participants do not necessarily provide a representative sample of the students at this institution, but nevertheless represents a sufficient sample for the purposes of this study.

It is appropriate to focus largely on the students' perspectives within a phenomenological framework. As students have unique insights into the phenomenon at hand, their immediate experiences and subjective consciousness are invaluable sources of information.

As the students were at no point identified during the forum, their anonymity is ensured. Indeed, the student identities are not even known to the authors of this article. Moreover, validity was achieved by both descriptive validity (i.e. 'the factual accuracy of the account' [Cohen et al. 2018:248]) and interpretive validity (i.e. 'the ability of the research to catch the meaning, interpretations, terms and intentions ... [of] the participants themselves, in their terms' [Cohen et al. 2018:248]). Furthermore, trustworthiness was achieved by the confirmability of the data as the video is publicly available and so satisfies the 'degree to which the findings of the research study could be confirmed by other researchers' (Korsten \& Moser 2018:121).

\section{Data analysis}

This paper explores a phenomenon from a South African perspective, namely academic integrity, during online assessments. It is also important to note that, at this stage, this research is exploratory. As Cohen et al. (2018:18) say, within an interpretive paradigm, the 'research [...] is exploratory in nature' and 'theory is emergent and arises from particular situations'. As qualitative data analysis centres on 'understanding, explaining and interpreting the phenomena in question', it is often 'heavy on interpretation' (Cohen et al. 2018:643).

The following steps were followed to analyse data from this video:

- Step 1: The video was used to generate transcripts in order to turn the audio-visual elements into the written word. The transcripts were meticulously edited to ensure accuracy. Each of the student voices was transcribed and saved in a separate file.

- Step 2: Transcripts were uploaded to Atlas.ti to facilitate the coding of the transcripts.

- Step 3: Open coding was used to code the transcripts. Cohen et al. (2018) explain the process of coding as creating small units out of larger pieces of texts by ascribing a 'category label to a piece of data, decided in advance or in response to the data that have been collected' (p. 668).

- Step 4: Once the initial coding process had been completed, 'groups' or 'networks' were created with similar themes. Two themes were created: 'reasons for cheating' and 'prevention of cheating'. The coding thus followed a deductive analysis - the data were generated and groups were created following a starting point: namely, the two questions posed to the students. These two questions then served as an organising framework for the coding process (Azungah 2018:391).

In what follows, the findings and the related literature are discussed. 


\section{Why is there dishonesty during (online) assessment?}

Students were asked two questions. The first question was 'Why do students cheat more during online teaching and assessments?' What became evident is that there are a variety of reasons why students choose to be dishonest. The following reasons emerged most strongly.

\section{Availability of content online}

Student 4 said, 'And another point is that students have access to quick answers', as well as:

'Or on the internet some way where a student can copy and paste and find their own answer. So technology has made learning much more convenient than a traditional way would have been in a normal circumstance.'

Student 8 said lecturers should ask less common questions 'because [the answers to common questions] is accessible from the internet.'

\section{Students feel overwhelmed and stressed}

Student 1 said:

'Especially in the cases of the final years, there's so much pressure already on them to finish the module, get accepted into honours, get work, etc. that when they don't understand the work, they tend to ask friends for help, and this can often lead to cheating.'

This was reiterated by Student 2 who said that:

'When it comes to online assessments and classes, students feel very overwhelmed and stressed and they want to stay on top of the coursework. So by cheating, it may alleviate this pressure.'

Similarly, Student 4 said: 'I think also all of these things that would normally be shown to cheat and to plagiarise is the fact that there's so much pressure and stress'. Student 5 related stress to poor time management, explaining that '[students] get overwhelmed because now they have to work, now they have to write a test and they still learning to go through all the unit's study material'.

These perspectives are echoed in the literature, where stress is highlighted as one of the main reasons for cheating (Eaton 2020; Gamage et al. 2020; McCabe 2016). When students are under extreme stress, for example, during examinations, they are more likely to make poor choices that can lead to academic misconduct (Eaton 2020:82).

\section{Pandemic-related issues}

Two students identified the COVID-19 pandemic as a reason for dishonesty. Student 2 highlighted the mental health issues, saying that 'COVID has had such an impact on not only just the student but any person's mental health and stress levels'. Student 10 had a different opinion on the negative mental effect of COVID: 'The global pandemic has forced students to take assignments, quizzes and tests from the comfort of their homes and rooms.'

The pandemic is a unique phenomenon, as it placed almost every student worldwide under pressure. The whole world has changed radically since COVID-19. One effect on university life is students' (and that of lecturers) stress level has increased. This is a variable that is difficult to gauge. Apart from the general stress of life during a pandemic, and potential illness and suffering that result from the pandemic, students remain under pressure to perform academically. The pandemic has raised the unemployment rate, so students have to compete even harder with one other (and peers from other universities) for jobs or scholarship opportunities. They are thus under immense pressure 'due to competitiveness in the job market' and 'massification and commercialisation of higher education' (Gamage et al. 2020:15).

\section{Lack of monitoring}

Many students agreed that the lack of monitoring was a significant contributor to academic dishonesty, as Student 2's comment illustrates:

'There's no actual monitoring that happens. There's no exam sitting, or anything like that, that can prevent them from cheating. And they obviously know this. So, they will take the opportunity to try and get above the coursework, but in a negative way.'

Student 3 took a similar line:

'Since everything is the online, and given that students are in an isolated system, students get that idea that no one is watching them, and that they think that it is easier to get away with cheating.'

\section{Both Student 4 and Student 5 agreed saying:}

'With online learning there isn't much of onsite facilitation or supervision when assessment quizzes or assignments are handed over, as in, in a normal circumstance face to face contact session will have some side supervision at all times. And that would be, for instance, an invigilator being paid for the duration of the time students have to write either an exam or a semester test.'

Student 5 said:

'I think it's also so much easier for students to cheat on an online platform as no one is monitoring the situation and ensuring that they don't use any resources for writing their test.'

The lack of monitoring was highlighted by Student 10:

'When a student is alone in their room completing a quiz, assignment or test, nothing is stopping them from referring back to the slides, textbook content and extra study material. There is no authority figure preventing it from happening.'

Lack of monitoring was an 'invitation to cheat' long before the pandemic. In a particular empirical study on online cheating, written well before the pandemic in 2008, 'Are online exams an invitation to cheat?', Harmon and Lambrinos (2008) found 
that 'cheating was taking place when the exams were not proctored' (p. 116). As Atoum et al. (2017) point out:

When exams are administered in a conventional and proctored classroom environment, the students are monitored by a human proctor throughout the exam. In contrast, there is no convenient way to provide human proctors in online exams. (p. 1)

Another reason for a potential increase in cheating, at least during the COVID-19 pandemic, is the reality that assessments were not designed for online purposes. Emergency remote learning - especially with regard to assessments - was not designed from the beginning in the same way as online learning is designed and implemented. Assessments could not be appropriately adjusted in time, and this created an opportunity for cheating. In general, the academic staff concerned had created tests, quizzes and examinations to be invigilated. When the situation made online assessment mandatory, there was not enough time to alter the assessments to ones that did not need proctoring. In short, there was no provision for ensuring that students would not be able to cheat during these assessment opportunities.

\section{Lack of time management}

Some students acknowledged that lack of time management leads to academic dishonesty. Student 3 said:

'Some students are unable to manage their time effectively and cannot cope with online learning. And therefore, workload becomes more in a short period, where [for] example some may realise that the test is due within 2 hours and therefore copying from friends becomes the only option because they panic and obviously do not want to lose the marks.'

Student 5 agreed: 'First of all, I think [students cheat] because students are not making time for their studies and to work through all the new week's study materials.' This student went on to say:

'[T]hey get overwhelmed because now they have to work, now they have to write a test and they still learning to go through all the unit's study material. And obviously, they still want good grades. So cheating is seen as the only option.'

The literature confirms that a lack of time to complete assessments is a common driver of dishonest behaviour (Brimble 2016).

\section{Lecturers recycling questions and allowing too much time for assessments}

Several responses also pointed to lecturers' assessment practices, especially 'recycling' assessments year after year. Student 4 said that students know that:

'Lecturers recycle material ... Students are comfortable in the fact that lecturers will not necessarily pull a strange question out of nowhere. But somehow, we'll have the question asked in past papers.'

They said that students 'cheat the system' because 'material is recycled. And there's so much of replicas of questions with quizzes and assignments that often have been done before and lecturers still ask similar questions.' Student 8 said that lecturers should 'go an extra mile and try to eradicate the repeating methods of asking questions.'

Eaton (2020) echoes this sentiment. She says one of the biggest challenges online teaching presents is:

[C]olleagues who continue to resist adapting their assessment practices to ones that are more appropriate for online learning and persist in their belief that students are the only ones responsible for maintaining academic integrity. (p. 83)

Another student pointed to the timing of online tests. Student 1 said that:

'Another reason can be that students all wrote at different times, so one, they can send the questions to others and two, there's no way to view the students themselves actually writing the test cases.'

\section{Academic inexperience}

Academic inexperience seems to be a telling reason why students resort to dishonesty. Student 1 acknowledged that:

'One of the reasons according to my point of view is that the students struggled to comprehend and understand the work on their own. Seeing that we mostly mean to make use of self study. Students need to teach themselves work and try to understand it.'

Academic inexperience has been a challenge as long before online teaching. In their research at Rhodes University in South Africa, Hendricks and Quinn found that students plagiarise because they struggle to integrate the ideas taken from the literature with their own ideas. They observe that students have difficulties 'using their own words and distinguishing different voices in writing' (Hendricks \& Quinn 2000:1). Lecturers need to offer assistance at the draft stage of the writing process to enable students to learn how knowledge is constructed.

\section{Struggling with technology}

Finally, Student 4 also identified technological struggles as a reason that students cheat. The participant said that:

'[S]tudents don't need to acquaint themselves with the fundamentals of knowing how to use online learning itself knowing how to use the internet, knowing how to use a folder, for example, Excel, therefore they would much rather opt for cheating the system [than getting the hang] of using technology.'

Remote delivery has 'restricted student access to information and support' (Gamage et al. 2020:10). Students in financially difficult positions struggle to buy data (although universities provided some data [Du Preez \& Le Grange 2020]), in addition to not having access to personal computing devices like a laptop or a desktop computer. Students, therefore, often rely on the campus Wi-Fi and computer laboratories to access learning management systems so they can do assessments. During the pandemic, these students do not have access to these support structures. At the same time, the frequent interruption of power supply (due to load shedding 
and cable theft) further limits students' access to online learning opportunities. This lack of access has led to a widening of the knowledge gap because the 'personhood and context of the student (user of technology) is ignored' (Du Toit \& Verhoef 2018:6). With the exclusive use of online learning and assessment, this becomes an even bigger challenge, which 'could eventually lead students to engage in acts of academic misconduct' (Gamage et al. 2020:10).

\section{What will stop online cheating by students?}

The second question that was asked was 'What will stop online cheating by students'? The response to this question is valuable as it gives academic institutions and staff some insight, not only into the reasons why students might be dishonest but also into how to address it. The findings will be presented along with literature about how universities have tried to curb dishonesty. Much of the discussion here focuses on assessment practices.

\section{Lecturers should ask different types of questions}

Many students made the suggestion that lecturers should change their assessment practices. In particular, they should ask different types of questions. Student 6 recommended that:

'Lecturers should set up questions that need deep understanding and should be more open minded, that is, answers to this question should not be easily found by website or Google.'

In a similar vein, Student 8 said that:

\begin{abstract}
'Allowing the students to apply their knowledge in knowledgebased questions in that way, everyone is able to apply their mind and give their point of view unlike a series of multiple-choice questions, true, false, match column A or B. This is a repetitive line of work, which does not for me, stimulate or enhance, or even equip a student the way in which it should ... So lecturers would need to come up with a way in which they structure questions in which they extract more information from learners, rather than asking common questions.'
\end{abstract}

Student 9 also supported the position that cheating could be stopped if the type of assessment used changed:

'I think we are using a more question and answer based approach, it can be changed to more application type of assessments, students will receive a test which they should download, complete and submit again, that has very little time amount. The questions asked can also be more scenario and application based, and not only knowledge based.'

Assessments need to be more appropriate for the online learning environment. At North-West University, for example, the NWU Working Group ${ }^{1}$ tried to counter the problem of dishonesty during and after the pandemic by

\footnotetext{
1.This Working Group of the North-West University (hereafter NWU Working Group) involved different role players at the NWU: a subject leader from each faculty, representatives of the Centre for Teaching and Learning and representatives from the Qualification and Programme Planning Office. The Working Group's responsibilities are (amongst others) to research and develop content for the compulsory 'Understanding the World' (UTW) modules at the NWU. These modules aim to address the development of NWU's graduate attributes, the NWU vision and mission and the values of the NWU.
}

giving a greater number of assessments and making them smaller assessments - so-called 'continuous assessment.' The students had to do all the tests, and the tests were designed to be part of the learning experience. Other assessment methods were introduced, like digital storytelling, online presentations, videos and memes. Questions were changed to include more case studies and to focus more on insight and application and less on content representation.

These changes were in line with other universities' diverse, innovative assessment practices and the recommendations in the relevant literature and research. These include more reflective assessments, 'student conferences as assessments' (Gamage et al. 2020:7), group reports, presentation of posters, podcasts and videos, presentations to a group of industry specialists (e.g. in the case of engineering students), legal advice in a virtual law clinic (law students), recording of 'hands-on experiments and virtual labs' (Asgari et al. 2020:8), oral examinations, 'using synthesis questions, peer grading' (McKenzie 2020:23), preparing 'different questions to different students' (Guangul et al. 2020:1) and 'giving students less time but simpler questions on tests' (Bilen \& Matros 2020:1). The idea is to reduce 'motivation to cheat by ensuring your assessment is meaningful and authentic' (IUA 2020:1).

\section{Practical suggestions}

Students also offered some practical suggestions to prevent dishonesty. Specifically, they suggested implementing group work, randomising assessment questions and imposing stricter time limits as ways to reduce online dishonesty. Student 7 said that group work could reduce dishonesty as:

\footnotetext{
'Students often learn better if they are collaborating with each other. And this is at least one way to ensure that cheating isn't happening because they are working together any way to the same goal. And they will each receive the same mark. So this would actually encourage them to put their best foot forward and work hard.'
}

Students 6 and 7 offered advice on randomising questions. Student 6 suggested 'questions should be set randomly. That is, this question should not be the same for everyone.' Similarly, Student 7 said that:

\footnotetext{
'Instead of having the same questions on assignments, or online activities or assessments, you can make use of question pools. So the question pool will have multiple different questions related to the topic.'
}

Another suggestion was about the timing of tests. In Student 6's view:

'Online tests should open and close at the same time. For example, if a lecturer sets up a 20 mark test for $30 \mathrm{~min}$, it should open, for example, 2:30 and close at 3 o'clock that very same day. In this way, students cannot share questions and answers or copy each other.'

\section{Proctoring}

Proctoring has a specific meaning in the online context. Invigilation in the United Kingdom 'is known as "proctoring" 
in the United States, which is why remote invigilation is also known as "online invigilation," "online proctoring" or "remote online proctoring"" (Gamage et al. 2020:10). Online invigilation takes place from any place through the Internet, with invigilators using their computers. Some students suggested implementing some sort of online supervision to curb dishonesty. Student 9 suggested that when taking a test:

'You're not allowed over any other tabs or browsers, you're not allowed to minimise Google and open another file ... So if you're writing a test, the lecturer can get an alert that you use Google or another tab or you opened another document.'

This was echoed by Student 10 who said:

'Maybe that all students must write a course assignment or test at the same time with the computer cameras on. This way they [sic] can be exam supervisors [invigilators] present to monitor all students.'

To counter the lack of monitoring, universities have introduced various measures, such as Turnitin, proctoring and adjusted assessments. However, online proctoring faces challenges, such as privacy concerns. According to Pierce (2020), the:

$[U]$ niversity of California Santa Barbara Faculty Association Board wrote a letter to campus administrators arguing that the use of ProctorU 'violates our students' rights to privacy', turning the university into a 'surveillance tool.'

Concerns have also been raised about protecting students' dignity and negatively affecting students 'with disabilities, students with children, and other groups who already face barriers in higher education' (Rose 2020).

Together with assessment changes, universities have begun to work more creatively and actively towards assessment security. These methods include the use of software to track dishonesty and plagiarism (Turnitin, iThenticate), setting 'strict assessment time limits' ( $\mathrm{Ng}$ 2020:610), not allowing backtracking, presenting questions one at a time and using technology for student verification. One of the strategies is to use proctoring software and services to secure online assessments.

However, it is not as straightforward as that. The use and success of proctoring are contested. Harmon and Lambrinos (2008), for example, argue:

The potential for a higher incidence of academic dishonesty in online courses than in face-to-face courses has been much discussed, and many authors have commented on the dearth of empirical evidence ... our results suggest that online exams administered in a proctored environment might equalise the incidence of academic dishonesty between online courses and face-to-face courses. (p. 123)

However, this positive evaluation of proctoring is not shared by all. There are a number of criticisms that could be levelled against it. The first is that proctoring can be costly depending on the specific equipment and software used. The second is that proctoring develops and encourages a policing culture. Some recommend, therefore, that proctoring through cameras and microphones should be avoided (Asgari et al. 2020:7). Miller (2020:1) notes that whilst proctoring might be effective, it strikes me as a crude approach, relying as it does on active surveillance, which creates an overt atmosphere of distrust. Naturally enough, there is also privacy concerns, as well as some anecdotal evidence that remote proctoring technology encodes racial biases.

A further critique against proctoring is that it might be counter-productive. In the policing environment it creates, students find more ingenious ways to cheat the system. A further objection is that it transforms the role of lecturers from academics, mentors or teachers to that of detectives trying to catch students in the act of cheating instead of teaching and helping them. This creates a highly distrustful environment where the 'academic staff may run into the risk of "categorising" all students as "criminals"' (Gamage et al. 2020:4). Therefore, the environment created by the use of online proctoring is not productive for student development. The same arguments also apply to the use of plagiarism (text-matching) detecting tools like Turnitin. Mphahlele and McKenna (2019) persuasively argue that text-matching software, like Turnitin, is 'misunderstood to be predominantly a plagiarism detecting tool for policing purposes, ignoring its educational potential for student development' (p. 1).

What became evident from this discussion is that students felt that lecturers carry some of the responsibility for curbing academic dishonesty. Some students felt that the onus was on the lecturer to set assessments that would prevent cheating. Others felt that students should be given less time to complete assessments, which would, in turn, reduce the time they have to find ways to be dishonest. Students said that online tests should be set up so that each student gets a different set of questions, less time should be given to complete the assessment, and online proctoring software should be used to discourage cheating. The challenges posed by using online proctoring and other dishonesty detection tools emphasise the need for fundamental change and rethinking strategies to address dishonesty and cheating more constructively. In our view, more nuanced pedagogical interventions are needed. In the next section, some recommendations are explored in the light of the above discussion.

\section{Fundamental changes needed to create and maintain academic integrity}

The lack of academic integrity in the digital domain, especially in the COVID-19 context, is not something that can be resolved with 'quick fix' answers. A more comprehensive, fundamental and sustainable approach is needed - one that is pedagogically nuanced and constructive. Fortunately, the literature provides a wealth of resources that assist in 
developing this approach. We will highlight some of these and propose some ideas of our own in this section. These address the issues raised by students and the shortcomings of existing attempts by universities to address these.

\section{Understanding academic integrity}

A complex but essential first step is to define academic integrity and what counts as academic dishonesty and cheating. It is clear from the above discussion that academic integrity should be understood as a commitment to certain values by both students and lecturers. Prohibiting behaviours will run counter to the principles of academic integrity. Deep commitment to academic integrity at universities whose staff and students have diverse cultural backgrounds, as in South Africa, will require care, effective communication and consensus. All of this will need to start from a relationship of trust.

\section{A relationship of trust}

When there had to be a sudden change to online assessments after the outbreak of the COVID-19 pandemic, the University of Calgary decided to 'start from a place of trust' (Eaton 2020:82) and prioritise people's fears, uncertainty and health at their institution. The message was clear that relationships, compassion and caring for each other - students and staff came first, and thereafter, academic integrity issues could be addressed. Mutual trust is a prerequisite for academic integrity. Students have to be able to trust the staff to set fair assessments and to grade fairly, whilst the staff have to be able to trust students not to cheat or plagiarise. Academic integrity protects both parties, and it requires a relationship of trust. This means lecturers need to recognise that students are not 'criminals', but partners in establishing an environment of academic integrity. It asks lecturers to be willing to 'recognise that students do not deliberately engage in academic misconduct' (Gamage et al. 2020:3) but often do not understand plagiarism or the software. This recognition has implications for mentorship and development.

However, building and maintaining a personal relationship with students - especially one built on trust - become extremely difficult during online teaching and learning. In the NWU Working Group, lecturers reported that the lack of physical or face-to-face contact (a bodily presence within the same space) with students makes the establishment of personal relationships extremely difficult. Lecturers find it demotivating to engage only with names on computer screens and have little or no chance of getting to know the persons behind the name. Face-to-face class discussions and debates and commitantly the experience of the human side of the academy (humour, emotion, verbal articulation, tone of voice, etc.) are generally absent in the online environment. This has a detrimental effect on personal relationships and the building of trust. There can be no doubt that live interaction is a crucial element in understanding the context and needs of the people involved (Du Toit \& Verhoef 2018:1). The challenge to lecturers and students who have to operate in an online environment is to commit to trusting each other despite being reduced to a black square in the online environment.

\section{Creating opportunities to develop values and ethics}

Other ways of building a joint commitment towards values that can enhance academic integrity have to be found. As mentioned above, this requires a team effort, 'a commitment not only from students but also from everyone involved in higher education' (Gamage et al. 2020:3). Not only should there be a clear academic integrity policy in place at universities, but there should also be opportunities for discussion and education on its vital role.

In this regard, the NWU Working Group identified the 'Understanding the World (UTW)' - modules to fulfil a specific role at the North-West University. The UTW modules are compulsory for all students and aim to address the development of the NWU's graduate attributes as described in the university's teaching and learning strategy:

[T] he University aims to educate graduates who will become lifelong learners and independent thinkers, able to manage knowledge creatively and effectively, exercise sound ethical judgement, and appreciate and value diversity in all its forms, respecting the diverse socio-economic and cultural contexts, natural environments, and workplaces. (NWU TL Strategy 2020:16)

These attributes complement the values that are part of academic integrity, which uniquely positions the UTW modules to play an integral role in it. Thus, the focus on developing an understanding, integration and commitment to certain values is crucial to developing values and ethics.

One of the aims of these UTW modules is to help students to be critical of their ethical perspectives and to develop an openness to growth in this area. As mentioned earlier, students have their own personal moral philosophy or set of ethical guidelines. The UTW modules, with their focus on developing graduateness, offer students some insights into their own moral perspectives and the way in which they make moral decisions. These modules deal with ethical issues and assist students in understanding why academic dishonesty is wrong and why academic integrity is a worthy ideal. One example is the importance of developing, promoting and committing to a code of honour. Miller (2020) states, for example, that:

$[H]$ onour pledges not only are surprisingly effective in curbing cheating; they also promote honesty. Students who abide by them refrain from cheating not because they can't, but because they choose not to. (p. 1)

The challenge is, according to Miller, to extend the impact of an honour code virtually as well.

\section{Continue to implement best practices}

Developing a more fundamental change at universities in terms of academic integrity is not a once-off activity. It is a 
'continuous process that needs to be sustained through regular initiatives' (Gamage et al. 2020:14). With constantly developing technology and changing student generations, constant work and communication are needed to maintain an environment of academic integrity. Some of the best practices in this regard have already been identified (before the emergency remote learning associated with COVID-19) and should be implemented continuously to have an impact. Universities need a proper system in place that monitors academic integrity because the reason for the 'poor implementation of academic integrity policy is that there is no proper system in place with officers specially dedicated to execute such a policy' (Gamage et al. 2020:13).

Some of the best practices at other higher education institutions, such as those at Universities Australia (UA), the IUA and the ICAI, can be usefully adopted. The IUA's guidelines are worth summarising here because they are in line with the main focus of this article. It lists five principles, namely:

1. The primacy of Institutional Autonomy. Universities have to take responsibility for ensuring academic integrity.

2. Everyone at the university is responsible for maintaining academic integrity.

3. A whole university approach is needed for minimising academic misconduct. Such a holistic approach combines (1) an educative focus on academic integrity policy dissemination, (2) a robust and fair process for dealing with breaches and (3) using data from reporting to improve teaching and learning.

4. Consistent and effective institutional policies and practices that focus on (1) educative measures, (2) different types of policy breach, (3) applicable penalties and (4) clear processes for investigating breaches.

5. Students should be engaged and empowered so they are as knowledgeable as possible about the nature of academic integrity decisions and the possible consequences (UA 2017:6-7).

These principles sketch the broader framework in which more detailed and pragmatic practices can be developed. This includes those from IUA, for instance, that are practicable and implementable.

\section{A serious threat to fight on a global scale}

The wide availability of contract cheating services has become an overwhelming threat or 'real ongoing challenge' (Gamage et al. 2020:12) to online academic integrity since COVID-19 lockdowns. Gamage et al. (2020) note that contract cheating websites:

$[P]$ rovide the option of doing the assessment in $2-3 \mathrm{~h}$; the student will pay more but there is no detection using the existing tools. They are sophisticated contract cheating services. (p. 12)

The QAA unpacked the issue of contract cheating and concluded that the development of organisation-wide detection methods and resources and support for staff is paramount to counter contract cheating (QAA 2020:8). This report also stressed the importance of positive approaches, such as emphasising academic integrity, rather than just focusing on censure (QAA 2020:18). Moreover, more fundamental changes should be sought, as argued in this article, to create an academic environment that prizes honesty and integrity.

\section{Conclusion}

Protecting academic integrity has been one of the main challenges during the COVID-19 pandemic as all learning and assessments moved to online platforms. It became easier to be dishonest, cheat and plagiarise in this context. It is nearly impossible to counter this with policing and surveillance methods. Even with the best technology and software available, students have opportunities to cheat. Universities should rather follow a more fundamental approach to ensuring an honest online academic environment. This approach is, of course, not only needed for online learning during COVID-19 but also after the pandemic. Online teaching and assessment will probably play a significant role in higher education in the future, and solutions need to be found for the long term. Fortunately, there are sound pedagogical guidelines to follow, as indicated in this article. However, the challenge of countering phenomena such as the growing global contract cheating business remains. Students who choose to make a commitment to academic integrity (as, for example, through honour pledges) play a vital role in this context.

This article has explored how different universities worldwide approach the challenges of academic integrity in an online environment to identify ways of transforming the higher education landscape to keep academic integrity intact. The review of the literature on COVID-19 and online assessments revealed a dearth of engagement with this issue in the South African context. In order to address this particular deficiency, data were generated by an institutional forum on academic dishonesty at University in South Africa in 2020. These data, brought into conversation with the best practices at international universities and the current literature on the topic, confirmed the need to address academic dishonesty during emergency remote online assessments. It seems that the way to address this issue lies in 'international' best practice combined with practicable strategies that take account of the unique needs in South Africa. Our findings and recommendations can be summarised as follows:

- Assessments should be designed to meet the needs of online learning. This means that lecturers have to shoulder their responsibility in this regard. They cannot merely shift the responsibility for maintaining academic integrity onto the students. For example, lecturers should be well informed on the availability of online content that students could use to answer assessment questions and assignments. They will also need to develop different types of questions or strategies that enhance learning in this context.

- Lecturers should bear in mind the huge stress that the COVID-19 pandemic is causing when they deal with issues related to academic integrity. They cannot just 
assume that students are engaging in deliberate academic honesty - especially when they are under tremendous pressure. Students are stressed and overwhelmed by the sudden change to only online learning and assessments, and sensitive guidance is necessary to guide them to commit to academic honesty within this context. This may include help with better time management by students but also better curriculum design by lecturers so that assessments are integrated in the online learning experience of students.

- In the South African context, students (and lecturers) also have to deal with technological challenges like the difficulty of accessing the internet, lack of data, electricity interruptions (due to load shedding and cable theft) and lack of technological support and devices (e.g. to resolve software problems). Furthermore, many South African students are first-generation university students who have very little academic experience and do not necessarily have the support of their immediate family members or peers. Within this context, lecturers should be as supportive as possible, whilst still ensuring that academic integrity is maintained.

- There should not be an over-reliance on plagiarism (or text similarity) identification tools like Turnitin or on proctoring methods. These can become counterproductive and downgrade the role of lecturers from academics and mentors to policing agents. This would undermine attempts to build and maintain a relationship of trust that is needed for a healthy academic environment. More nuanced pedagogical interventions are thus needed.

- Continuous development of ethics and values through different programmes at the university is needed. In this regard, the management of universities should take the lead to ensure various initiatives are taken to develop a culture of honesty. One example that could be explored is honour codes to which students and lecturers are asked to subscribe.

- A holistic approach by students, lecturers and university management is needed to create and maintain academic integrity. All three of these role players should take responsibility to ensure that a culture of academic honesty is maintained. The best practices of various international universities give very good guidance in this regard and apply to the South African context, but we also need to keep the unique South African challenges in mind when developing our own strategies to maintain academic integrity.

\section{Acknowledgements Competing interests}

The authors declare that they have no financial or personal relationships that may have inappropriately influenced them in writing this article.

\section{Authors' contributions}

The authors contributed equally to the writing of this article.

\section{Ethical considerations}

This article followed all ethical standards for research without direct contact with human or animal subjects.

\section{Funding information}

This research received no specific grant from any funding agency in the public, commercial or not-for-profit sectors.

\section{Data availability}

Data sharing is not applicable to this article as no new data were created or analysed in this study.

\section{Disclaimer}

The views and opinions expressed in this article are those of the authors and do not necessarily reflect the official policy or position of any affiliated agency of the author.

\section{References}

Asgari, S., Trajkovic, J., Rahmani, M., Zhang, W., Lo, R.C. \& Sciortino, A., 2020, 'An observational study of engineering online education during the COVID-19 pandemic', PLOS One 16(4), e0250041. https://doi.org/10.1371/journal. pone.0250041

Atoum, Y., Chen, L., Liu, A.X., Hsu, S.D. \& Liu, X., 2017, 'Automated online exam proctoring', IEEE Transactions on Multimedia 19(7), 1609-1624. https://doi. org/10.1109/TMM.2017.2656064

Azungah, T., 2018, 'Qualitative research: Deductive and inductive approaches to data analysis', Qualitative Research Journal 18(4), 383-400. https://doi.org/10.1108/ QRJ-D-18-00035

Bilen, E. \& Matros, A., 2020, 'Online cheating amid COVID-19', in Munich personal RePEC archive, pp. 3-26, viewed 1 February 2021, from https://mpra.ub.unimuenchen.de/103185/.

Brimble, M., 2016, 'Why students cheat: An exploration of the motivators of student academic dishonesty in higher education', in T. Betag (ed.), 1st edn., pp. 365-380, Springer Science + Business Media Singapore Pty Ltd., Singapore.

Cohen, L., Manion, L. \& Morrison, K., 2018, Research methods in education, 8th edn. Routledge, New York, NY.

Du Preez, P. \& Le Grange, L., 2020, 'The COVID-19 pandemic, online teaching/learning, the digital divide, and epistemological access', in L. Ramrathan, N. NdimandeHlongwa, N. Mkhize \& J.A. Smit (eds.), Alternation African Scholarship Book Series: Vol. 1. Re-thinking the humanities curriculum in the time of COVID-19, pp. 90-106, CSSALL, Durban.

Du Toit, J. \& Verhoef, A.H., 2018, 'Embodied digital technology and transformation in higher education', Transformation in Higher Education 3(0), a52. https://doi. org $/ 10.4102 /$ the. v3i0.52

Eaton, S.E., 2020, 'Academic integrity during COVID-19: Reflections from the University of Calgary', International Studies in Educational Administration 48(1), 80-85.

Elsalem, L., Al-Azzam, N., Jum'ah, A.A. \& Obeidat, N., 2021, 'Remote e-exams during Covid-19 pandemic: A cross-sectional study of students' preferences and academic dishonesty in faculties of medical sciences', Annals of Medicine and Surgery 62, 326-333. https://doi.org/10.1016/j.amsu.2021.01.054

Elzainy, A., El Sadik, A. \& Al Abdulmonem, W., 2020, 'Experience of e-learning and online assessment during the COVID-19 pandemic at the College of Medicine, Qassim University', Journal of Taibah University Medical Sciences 15(6), 456-462. https://doi.org/10.1016/j.jtumed.2020.09.005

Feathers, T. \& Rose, J., 2020, 'Students are rebelling against eye-tracking exam surveillance tools', Vice, viewed 01 July 2021, from https://www.vice.com/en/ article/n7wxvd/students-are-rebelling-against-eye-tracking-exam-surveillancetools

Gamage, K.A.A., De Silva, E.K. \& Gunawardhana, N., 2020, 'Online delivery and assessment during COVID-19: Safeguarding academic integrity', Education Sciences 10(301), 1-24. https://doi.org/10.3390/edusci10110301

Guangul, F.M., Suhail, A.H., Khalit, M.I. \& Khidhir, B.A., 2020, 'Challenges of remote assessment in higher education context of Covid-19: A case study of Middle East College. Educational Assessment, Evaluation and Accountability. 32, 519-535. https://doi.org/10.1007/s11092-020-09340-w

Harmon, O.R. \& Lambrinos, J., 2008, 'Are online exams an invitation to cheat?', The Journal of Economic Education 39(2), 116-125. https://doi.org/10.3200/ JECE.39.2.116-125

Hendricks, M. \& Quinn, L., 2000, 'Teaching referencing as an introduction to epistemological empowerment', Teaching in Higher Education 5(4), 1-11. https:// doi.org/10.1080/713699175 
Hodges, C., Moore, S., Trust, T. \& Bond, A., 2020, 'The difference between emergency remote teaching and online learning', Educause Review, viewed 01 February
2021 , from https://er.educause.edu/articles/2020/3/the-difference-betweenemergency-remote-teaching-and-online-learning.

https://www.youtube.com/watch?v=SjNtOXqpJAo.

International Center for Academic Integrity (ICAI), 2012, Statistics: Overview, viewed 01 June 2021, from http://www.academicintegrity.org/icai/integrity-3.php.

International Center for Academic Integrity (ICAI), 2021, The fundamental values of academic integrity, 3rd edn., viewed 01 June 2021, from www.academicintegrity. org/the-fundamental-valuesof-academic-integrity.

Irish Universities Association (IUA), 2020, viewed 14 April 2021, from www.iua.ie/ publications/academic-integrity-in-onlineassessment/.

Jose, A.S., 2021, Academic Integrity during COVID 19 Pandemic. A student perspective, GRIN Verlag, Munich, viewed 16 July 2021, from https://www.grin.com/ document/1012391.

Marques, T., Reis, N. \& Gomes, J., 2019, 'A bibliometric study on academic dishonesty research', Journal of Academic Ethics 17(2), 169-191. https://doi.org/10.1007/ s10805-019-09328-2

McCabe, D., 2016, 'Cheating and honor: Lessons from a long-term research project', in Y.T. Bretag (ed.), Handbook of academic integrity, pp. 187-198, Springer, Singapore.

McKenzie, A., 2020, 'COVID-19: A silver lining for academic integrity from a pandemic', Canadian Perspectives on Academic Integrity 3(2), 1-3. https://doi.org/10.11575/ cpai.v3i2.71644

Miller, C.B., 2020, 'Just how dishonest are most students?', The New York Times, viewed 22 April 2021, from https://www.nytimes.com/2020/11/13/opinion/ sunday/online-learning-cheating.html.

Mphahlele, A. \& McKenna, S., 2019, 'The use of turnitin in the higher education sector: Decoding the myth', Assessment \& Evaluation in Higher Education 44(7), 1079-1089. https://doi.org/10.1080/02602938.2019.1573971

Newton, P.M. \& Lang, C., 2016, 'Custom essay writers, freelancers, and other paid third parties', in Y.T. Bretag (ed.), Handbook of academic integrity, pp. 249-271 Springer, Singapore.

Ng, C.K.C., 2020, 'Evaluation of academic integrity of online open book assessments implemented in an undergraduate medical radiation science course during COVID-19 pandemic', Journal of Medical Imaging and Radiation Sciences 51 610-616. https://doi.org/10.1016/j.jmir.2020.09.009

Ngqondi, T., Maoneke, P.B. \& Mauwa, H., 2021, 'A secure online exams conceptua framework for South African universities', Social Sciences \& Humanities Open 3(1), 100132. https://doi.org/10.1016/j.ssaho.2021.100132
North-West University, 2018, North West University Policy on Academic Integrity, 2018 , viewed 20 June 2021, from http://www.nwu ac za/sites/www.nwu ac za/ files/files/i-governance-management/policy/Policies $\% 20-\% 202020 \% 20$ Update/2P-2.4.3.2_Academic\%20integrity_e.pdf.

North-West University, 2020, North-West University Teaching and Learning Strategy, 2020, viewed 20 June 2021, from http://www.nwu.ac.za/sites/www.nwu.ac.za/ files/files/i-governance-management/documents/T\%26L-Strategy-2021-2025.pdf.

Owings, S. \& Nelson, J., 2014, 'The essay industry', Mountain Plains Journal of Business and Economics 15(1), viewed 19 June 2021, from https://openspaces.unk.edu/ $\mathrm{mpjbt} / \mathrm{vol} 15 /$ iss $1 / 1$.

Pierce, D., 2020, 'Online proctoring keeps remote exams secure but raises privacy questions', eCampus News, viewed 01 July 2021, from https://www.ecampusnews. $\mathrm{com} / 2020 / 09 / 04 /$ online-proctoring-keeps-remote-exams-secure-but-raisesprivacy-questions/2/

Quality Assurance Agency, 2020, Contracting to cheat in higher education: How to address essay mills and contract cheating, viewed 01 June 2020, from https:// www.qaa.ac.uk/docs/qaa/guidance/contracting-to-cheat-in-higher-education2nd-edition.pdf.

Reedy, A., Pfitzner, D., Rook, L. \& Ellis, L., 2021, 'Responding to the COVID-19 emergency: Student and academic staff perceptions of academic integrity in the transition to online exams at three Australian universities', International Journal of Educational Integrity 17, 9. https://doi.org/10.1007/s40979-021-00075-9

Robinson, R.S., 2014, 'Purposive sampling', in A.C. Michalos (eds.), Encyclopedia of quality of life and well-being research, pp. 227-311, Springer, Dordrecht.

Rodchua, S., 2017, 'Effective tools and strategies to promote academic integrity in e-learning', International Journal of e-Education, e-Business, e-Management and e-Learning 7(3), 168-179. https://doi.org/10.17706/ijeeee.2017.7.3.168-179

UNESCO, 2021, Education: From disruption to recovery, viewed 01 June 2021, from https://en.unesco.org/covid19/educationresponse.

Universities Australia (UA), 2017, UA academic integrity best practice principles, viewed 23 April 2021, from https://www.universitiesaustralia.edu.au/wp content/uploads/2019/06/UA-Academic-Integrity-Best-Practice-Principles.pdf.

Wallace, M.J. \& Newton, P.M., 2014, 'Turnaround time and market capacity in contract cheating', Educational Studies 40(2), 233-236. https://doi.org/10.1080/03055698. 2014.889597

Witherspoon, M., Maldonado, N. \& Lacey, C.H., 2010, 'Academic dishonesty of undergraduates: Methods of cheating', Paper presented at the Annual Meeting of the American Educational Research Association, 30 April - 4 May 2010, Denver, CO. 